\title{
Histone modification and replacement in chromatin activation
}

\author{
Mary Grace Goll and Timothy H. Bestor ${ }^{1}$ \\ Department of Genetics and Development, College of Physicians and Surgeons of Columbia University, \\ New York, New York 10032
}

Histones are subject to a complex and dynamic set of covalent modifications that are thought to be involved in the modulation of transcription during development, in $\mathrm{X}$ chromosome inactivation in female mammals, and in genome stability and meiotic chromosome dynamics. Histone modifications reported to date include acetylation, phosphorylation, methylation, ADP ribosylation, and ubiquitination (Fig. 1). Multiple residues on each of the four core histones have been identified as potential modification sites and some lysine side chains can be either methylated or acetylated. Given the number of sites and the variety of possible modifications, the combinatorial possibilities are extremely large and it is tempting to believe that histone modification has a regulatory role. This led to the histone code hypothesis, which postulated that these modifications may be interdependent and that they may culminate in specific histone landscapes that provide entry sites for proteins responsible for higher order chromatin organization and gene activation or inactivation (Strahl and Allis 2000; Jenuwein and Allis 2001). Provided that patterns of histone modifications are subject to mitotic inheritance, their net effect will be an increase in the information content of the genome. However, the complexity of the process and the fact that chromatin structure remains poorly defined (except when presented as candy-colored PowerPoint cartoons) has hidden the real nature of the impact of histone modifications on the structure and regulated expression of the genome, and the magnitude of the effects exerted by different histone modifications has been difficult to assess from biochemical data. The lack of a candidate mechanism that could mediate clonal transmission of patterns of histone modifications has also been a problem. Surprising recent data indicate that the nucleosome does not merely serve as an armature for informational posttranslational modification, but rather that the act of transcription causes the introduction of a histone $\mathrm{H} 3$ variant $(\mathrm{H} 3.3)$ that attracts activating histone modifications and directly participates in the assembly of chromatin configurations favorable for

${ }^{1}$ Corresponding author.

E-MAIL THB12@columbia.edu; FAX (212) 740-0992.

Article and publication are at http://www.genesdev.org/cgi/doi/10.1101/ gad.1013902. transcription (Ahmad and Henikoff 2002). Although important questions remain to be answered, recent progress in the genetic analysis of histone modification has provided a new foundation for chromatin biology.

\section{Histone methylation}

Jenuwein and colleagues (Rea et al. 2000) were the first to realize that many (but not all) mammalian proteins that contain a SET (Suppressor of Variegation, Enhancer of Zeste, and Trithorax) domain are histone lysine methyltransferases. The closely-related SET domain proteins Suv39h1 and Suv39h2 were shown to be essential for normal histone methylation within heterochromatin; deletion of Suv39h1 and Suv39h2 genes (the double mutant will be referred to as Suv39h-null) reduced net methylation of histone $\mathrm{H} 3$ lysine 9 (H3-K9) by approximately one-half, and in wild-type cells Suv39h1 was seen to colocalize with the Polycomb group protein HP1 at heterochromatic regions of interphase nuclei. Suv39hnull mice were born at sub-Mendelian ratios and showed growth retardation and meiotic chromosome segregation defects (Peters et al. 2001). These and other data implicated Suv39h in the methylation of histones within the heterochromatic compartment of the nucleus.

In this issue, Tachibana et al. (2002) report on the phenotype of mice that lack a second H3-K9 methyltransferase that acts in the euchromatic compartment. Loss of this histone methyltransferase (G9a) reduced total levels of H3-K9 methylation to approximately one-eighth of wild type (versus one-half in the Suv39h null mutant), and residual H3-K9 methylation was localized to pericentric heterochromatin, where histones are undermethylated in the Suv39h null mutant. G9a-deficient mice showed defects in Lys 9 methylation at euchromatic sites and suffered a more severe phenotype than did Suv39h null mutants. Developmental arrest and embryonic death occurred around 9 d post-coitus, with cellcycle defects and apoptosis in embryos and in differentiating cells derived from them, although homozygous mutant embryonic stem (ES) cells grew normally in culture.

In Drosophila, H3-K9 methylation demonstrates an intimate association both with cytological heterochromatin and the heterochromatin binding protein HP1 
H3

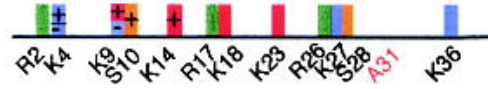

H3.3

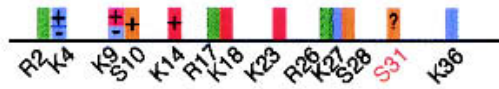

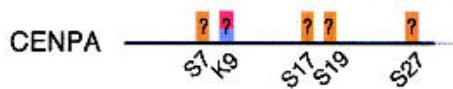

$\mathrm{H} 4 \mathrm{HI|⿴囗十⺝}$

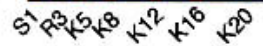

H2A

$\mathrm{H} 2 \mathrm{~B}$

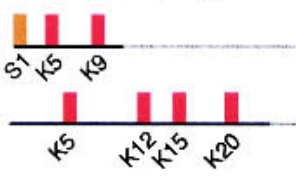

$\mathrm{H} 2 \mathrm{~B}$

$\left\|\mathrm{PO}_{4}\right\| \mathrm{AC}\|\mathrm{K}-\mathrm{Me}\| \mathrm{R}-\mathrm{Me} \| \mathrm{ub}$

Figure 1. Histone sites subject to covalent modification. $(+)$ Sites subject to the indicated modification in actively transcribed chromatin; (-) modifications associated with repressed chromatin; (?) potential but unproven sites of modification. Histone H3.3 has a potential site of phosphorylation at Ser 31 that is absent from $\mathrm{H} 3$ (gold). Gray lines indicate globular portions whose modification status is unknown. Ac, acetyl; K-Me, mono- or dimethyllysine; R-Me, methylarginine; and Ub, ubiquitin.

(Cleard et al. 1997). It has been shown recently that the HP1 chromodomain specifically binds histone H3 N-terminal tails when those tails are methylated at Lys 9 (Bannister et al. 2001; Lachner et al. 2001; Jacobs and Khorasanizadeh 2002). Although these data suggest that H3-K9 methylation might be largely restricted to the heterochromatic compartment of the nucleus, the current work by Tachibana et al. (2002) suggests that, at least in mammalian systems, much more histone methylation resides in euchromatin than heterochromatin. As mentioned above, mice that are null for Suv39h retain $\sim 50 \%$ of Lys 9 methylation, whereas less than $20 \%$ of methylation remains in G9a null mice. Although strong overlap of HP1 and Suv39h proteins are seen in interphase nuclei, only a very minor fraction of G9a protein is seen to colocalize with HP1.

It had been suggested previously that two distinct modification states were interchanged by means of a switch between H3-K9 methylation and H3 Ser 10 phosphorylation (Rea et al. 2000). A clear interdependence was demonstrated in vivo in the Suv39h mutant mouse, as $\mathrm{H} 3$ Ser 10 phosphorylation levels were significantly increased (Peters et al. 2001). In the Hdac1-null mouse embryo, which has a deletion of the major histone deacetylase of mammals, overall hyperacetylation was associated with decreased methylation at H3-K9 and increased phosphorylation at Ser 10 (Lagger et al. 2002). In the G9a mouse, however, Ser 10 phosphorylation levels were not affected despite a much greater general decrease in Lys 9 methylation as compared to the Suv39h mutants. It may be that Lys 9 methylation mediates transcriptional modulation in euchromatic regions, whereas its role in heterochomatin is related to chromosome structure. An interesting question that stems from this seeming distinction in function is how two different Lys 9 methylation events might be distinguished. One potential difference might be the ability of G9a to also methylate Lys 27 in vitro (Tachibana et al. 2001).

\section{Limited gene dysregulation after disruption of histone codes}

Histone codes were proposed to be established by regulatory factors and to govern the rate of transcription of chromatin domains (for review, see Wolffe 2001). In the extreme view, histone modification could be regarded as the primary role of a large set of transcription factors. Genetic ablation of histone methyltransferases or histone deacetylases and acetyltransferases provide a stringent experimental test of the histone code hypothesis in the regulation of eukaryotic transcription. The first set of results suggests that transcriptional control is relatively robust to alterations in histone modification.

Tachibana et al. (2002) performed microarray analysis on ES cells that lack G9a and found dysregulation only of genes of the melanoma antigen gene (MAGE) family, which encode tumor antigens of unknown function. This finding is consistent with the phenotype of G9anull embryos, which complete the early stages of embryogenesis normally whereas mice that lack key components of the RNA polymerase II complex die at cleavage stages (de Boer et al. 1998). Neither global defects in transcription nor dysregulation of specific genes have been reported in mice that lack Suv39h, and genomewide hyperacetylation in mouse embryos that lack Hdacl has not been reported to induce large-scale transcription defects (Lagger et al. 2002).

An especially urgent question concerns the role of histone modification in epigenetic gene silencing, which involves the mitotic transmission of states of gene inactivity in a manner that is largely insensitive to the presence of all the factors normally required for the expression of the particular gene. In mammals, long-term epigenetic control is seen largely at imprinted loci ( $\mathrm{Li}$ et al. 1993), genes on the inactive X chromosome of females (Panning and Jaenisch 1996), and at the very large number of transposon-related sequences that make up at least 
$45 \%$ of the genome (Yoder et al. 1997; Walsh and Bestor 1999|. Additional transient silencing events involve the Hox gene clusters during early embryonic development (for review, see Gebuhr et al. 2000), the preferential silencing of the paternal $\mathrm{X}$ chromosome in extraembryonic tissues of mouse embryos (Takagi and Sadaki 1975), and the inactivation of the sole $\mathrm{X}$ chromosome during spermatogenesis (Salido et al. 1992). Long-term gene silencing has been shown to depend on the methylation of cytosine residues in DNA (for review, see Yoder et al. 1997; Bestor 2000), whereas transient silencing of Hox genes (for review, see Gebuhr et al. 2000) and of the paternal X chromosome in extraembryonic tissues (Wang et al. 2001) requires proteins of the Polycomb and trithorax groups. Little is known of the mechanisms that mediate inactivation of the $\mathrm{X}$ chromosome during spermatogenesis. To date there is not much direct evidence for a dependence of genomic imprinting, $\mathrm{X}$ inactivation, or transposon silencing on histone modification. Imprinting defects have not been reported in embryos that bear hypomethylated chromatin as a result of deprivation of Suv39h or G9a, nor has hypoacetylation or hyperacetylation caused by removal of histone acetyltransferases or histone deacetylases been shown to relieve gene silencing. It is especially notable that while the inactive $\mathrm{X}$ chromosome is clearly hyperacetylated (Jeppesen and Turner 1993), defects in X inactivation have not been reported in embryos deficient in histone acetyltransferases or deacetylases, and histone demethylation in Suv39h- or G9a-null mouse embryos does not appear to affect $\mathrm{X}$ inactivation, as shown by indistinguishable phenotypes in male and female embryos (Peters et al. 2001; Tachibana et al. 2002). The importance of histone modification in gene silencing in mammals remains to be determined, although results of initial genetic studies do not indicate a central role.

\section{Histone methylation and DNA cytosine methylation}

The possibility that genomic methylation patterns might be controlled by the methylation status of histones emerged from genetic studies in the ascomycete fungus Neurospora crassa (Tamaru and Selker 2001), in which the dim 5 mutation that caused loss of genomic 5-methylcytosine was found to inactivate a SET domain histone methyltransferase. The finding that the KRYPTONITE gene of Arabidopsis thaliana, which is required for the maintenance of $\mathrm{CpNpG}$ methylation at silenced reporter constructs, also encodes a histone methyltransferase (Jackson et al. 2002) evoked the suggestion that DNA methylation might only be a secondary effect of histone methylation (Richards and Elgin 2002). However, neither experimental data nor comparative biology considerations support this view, and there is little evidence to link histone modification and cytosine methylation in mammals. The behavior of genomic methylation patterns in mammals and fungi are very different, as shown by the fact that DNA methylation is fully dispensable in Neurospora whereas even partial erasure of methylation patterns in mammalians ge- nomes is lethal (Li et al. 1992). Cytosine methylation inhibits elongation but not initiation in Neurospora (Rountree and Selker 1997), whereas the opposite is true of mammals (Kass et al. 1997). Hyperacetylation of histones after treatment of Neurospora with trichostatin A causes demethylation of specific regions of the genome (Selker 1998), whereas histone hyperacetylation has not been reported to alter genomic methylation patterns in mammals. Furthermore, Jackson et al. (2002) report that demethylation of DNA in KRYPTONITE mutants occurred only at $\mathrm{CpNpG}$ sequences and not at $\mathrm{CpG}$ sequences; $\mathrm{CpG}$ methylation appears to rely on proteins that are well conserved between plants and animals. CpNpG methylation depends on the CMT3 chromomethylase, which bears a chromo domain that is likely to be involved in the recognition of methylated histones and to target cytosine methylation to the vicinity of methylated nucleosomes (Jackson et al. 2002). Mammals lack the chromomethylase family altogether, and CpNpG methylation is rare, if it occurs at all, in the mammalian genome. There is in fact little evidence of an interaction between cytosine methylation and histone modifications of any type in mammals. Prior reports of recruitment of histone deacetylases via $\operatorname{Sin} 3 \mathrm{~A}$ and the methylcytosine-binding protein $\mathrm{MeCP} 2$ (for review, see Bestor 1998) are of questionable biological significance in view of the normal epigenetic silencing in mice that lack MeCP2 (Chen et al. 2001).

\section{Histone modification or histone replacement?}

The histone code hypothesis envisions the nucleosome as a relatively static armature for decoration by covalent modification. According to this view the modifications convey information but the nucleosome itself does not. A surprising new study from Ahmad and Henikoff (2002) suggests that the constellation of histone modifications may be the result of transcription-coupled replacement of histone H3 (normally incorporated into chromatin during $\mathrm{S}$ phase) with the variant or replacement histone $\mathrm{H} 3.3$, which is incorporated into chromatin during $\mathrm{G}_{1}$ and $G_{2}$ phases. The authors used histone-GFP fusion constructs to demonstrate replication-independent deposition of histone $\mathrm{H} 3.3$ at sites of transcriptionally active rDNA arrays in Drosophila. They further demonstrated that H3.3 deposition appears at normally silent rDNA arrays when transcription is activated by altered growth conditions, and other data indicate that this H3.3 deposition is not rDNA-specific but is characteristic of transcriptionally active euchromatic regions.

The deposition of a novel histone variant at transcriptionally active genes provides a revolutionarily different view of chromatin remodeling in which histone replacement itself is informational and is the catalyst for covalent modification of nucleosomes in patterns characteristic of transcriptionally active chromatin. In this view, histone modifications are a consequence, rather than a cause, of transcriptional activity. The sequence of histone H3.3 suggests a mechanism for changes in chromatin state upon replacement of $\mathrm{H} 3$ with $\mathrm{H} 3.3$, which differ 
at four residues: Three of these are located within the histone core and are involved in targeting H3.3 for replication-independent incorporation, the fourth amino acid difference lies at position 31 in the $\mathrm{N}$-terminal histone tail (Fig. 1). This position is an alanine in $\mathrm{H} 3$ but a serine in H3.3. Ahmad and Henikoff (2002) suggest that phosphorylation of this serine residue may be the signal for the modification of amino acid sidechains elsewhere in H3.3 in patterns characteristic of actively transcribed genes. As preexisting histone modifications are eliminated by exchange of histones, the histone replacement model also provides a mechanism by which the inhibitory effects of histone methyltransferases such as G9a can be reversed; this was formerly a problem, as histone demethylases have not been reported. Recent findings are bringing us closer to an understanding of the relationship and relative importance of histone replacement and histone modification in chromatin biology and epigenetics.

\section{References}

Ahmad, K. and Henikoff, S. 2002. The histone variant H3.3 marks active chromatin by replication-independent nucleosome assembly. Mol. Cell 9: 1191-1200.

Bestor, T.H. 1998. Gene silencing. Methylation meets acetylation. Nature 393: 311-312.

Bestor, T.H. 2000. The DNA methyltransferases of mammals. Hum. Mol. Genet. 9: 2395-2402.

Chen, R.Z., Akbarian, S., Tudor, M., and Jaenisch, R. 2001. Deficiency of methyl-CpG binding protein-2 in CNS neurons results in a Rett-like phenotype in mice. Nat. Genet. 27: 327-331.

Cleard, R., Delatorre, M., and Spierer, P. 1997. SU(VAR)3-7, a Drosophila heterochromatin associated protein and companion of HP1 in the genomic silencing of position-effect variegation. $E M B O ~ J$. 16: 5280-5288.

de Boer, J., Donker, I., de Wit, J., Hoeijmakers, J.H., and Weeda, G. 1998. Disruption of the mouse xeroderma pigmentosum group D DNA repair/basal transcription gene results in preimplantation lethality. Cancer Res. 58: 89-94.

Gebuhr, T.C., Bultman, S.J., and Magnuson, T. 2000. Pc-G/ trx-G and the SWI/SNF connection: Developmental gene regulation through chromatin remodeling. Genesis 26: 189197.

Jackson, J.P., Lindroth, A.M., Cao, X., and Jacobsen, S.E. 2002. Control of CpNpG DNA methylation by the KRYPTONITE histone H3 methyltransferase. Nature 416: 556-560.

Jacobs, S.A. and Khorasanizadeh, S. 2002. Structure of HP1 chromodomain bound to a lysine 9-methylated histone tail. Science 295: 2080-2083.

Jeppesen, $\mathrm{P}$ and Turner, B.M. 1993. The inactive $\mathrm{X}$ chromosome in female mammals is distinguished by a lack of histone $\mathrm{H} 4$ acetylation, a cytogenetic marker for gene expression. Cell 74: 281-289.

Kass, S.U., Landsberger, N., and Wolffe, A.P. 1997. DNA methylation directs a time-dependent repression of transcription initiation. Curr. Biol. 7: 157-165.

Lagger, G., O'Carroll, D., Rembold, M., Khier, H., Tischler, J., Weitzer, G., Schuettengruber, B., Hauser, C., Brunmeir, R., Jenuwein, T., et al. 2002. Essential function of histone deacetylase 1 in proliferation control and CDK inhibitor repression. EMBO I. 21: 2672-2681.
Li, E., Bestor, T.H., and Jaenisch, R. 1992. Targeted mutation of the DNA methyltransferase gene results in embryonic lethality. Cell 69: 915-926.

Li, E., Beard, C., and Jaenisch, R. 1993. Role for DNA methylation in genomic imprinting. Nature 366: 362-365.

Panning, B. and Jaenisch, R. 1996. DNA hypomethylation can activate Xist expression and silence X-linked genes. Genes \& Dev. 10: 1991-2002.

Peters, A.H., O'Carroll, D., Scherthan, H., Mechtler, K., Sauer, S., Schofer, C., Weipoltshammer, K., Pagani, M., Lachner, M., Kohlmaier, A., et al. 2001. Loss of the Suv39h histone methyltransferases impairs mammalian heterochromatin and genome stability. Cell 107: 323-337.

Rea, S., Eisenhaber, F., O'Carroll, D., Strahl, B.D., Sun, Z.W., Schmid, M., Opravil, S., Mechtler, K., Ponting, C.P., Allis, C.D., and Jenuwein, T. 2000. Regulation of chromatin structure by site-specific histone H3 methyltransferases. Nature 406: 593-599.

Richards, E.J. and Elgin, S.C. 2002. Epigenetic codes for heterochromatin formation and silencing: Rounding up the usual suspects. Cell 108: 489-500.

Rountree, M.R. and Selker, E.U. 1997. DNA methylation inhibits elongation but not initiation of transcription in Neurospora crassa. Genes \& Dev. 11: 2383-2395.

Salido, E.C., Yen, P.H., Mohandas, T.K., and Shapiro, L.J. 1992. Expression of the X-inactivation-associated gene XIST during spermatogenesis. Nat. Genet. 2: 196-199.

Tachibana, M., Sugimoto, K., Fukushima, T., Shinkai, Y. 2001. SET domain-containing protein, G9a, is a novel lysine-preferring mammalian histone methyltransferase with hyperactivity and specific selectivity to lysines 9 and 27 of histone H3. J. Biol. Chem. 276: 25309-25317.

Takagi, N. and Sadaki, M. 1975. Preferential inactivation of the paternally derived $\mathrm{X}$ chromosome in the extra embryonic membranes of the mouse. Nature 256: 640-642.

Tamaru, H. and Selker, E.U. 2001. A histone H3 methyltransferase controls DNA methylation in Neurospora crassa. $\mathrm{Na}$ ture 414: 277-283.

Walsh, C.P. and Bestor, T.H. 1999. Cytosine methylation and mammalian development. Genes \& Dev. 13: 26-34.

Wang, J., Mager, J., Chen, Y., Schneider, E., Cross, J.C., Nagy, A., and Magnuson, T. 2001. Imprinted $\mathrm{X}$ inactivation maintained by a mouse Polycomb group gene. Nat. Genet. 28: $371-375$.

Wolffe, A.P. 2001. Transcriptional regulation in the context of chromatin structure. Essays Biochem. 37: 45-57.

Yoder, J.A., Walsh, C.P., and Bestor, T.H. 1997. Cytosine methylation and the ecology of intragenomic parasites. Trends Genet. 13: 335-340. 


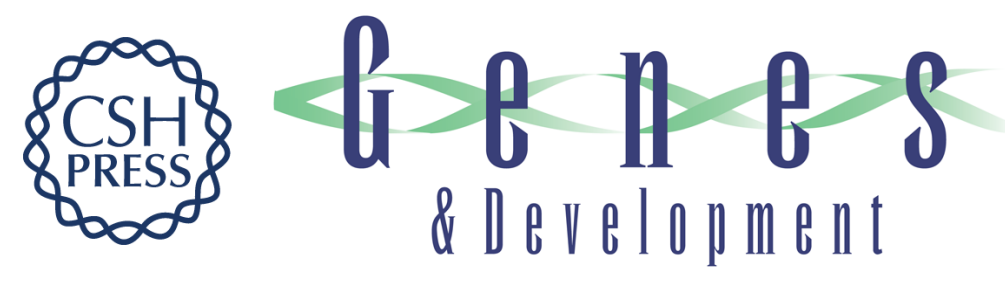

\section{Histone modification and replacement in chromatin activation}

Mary Grace Goll and Timothy H. Bestor

Genes Dev. 2002, 16:

Access the most recent version at doi:10.1101/gad.1013902

References This article cites 27 articles, 8 of which can be accessed free at: http://genesdev.cshlp.org/content/16/14/1739.full.html\#ref-list-1

License

Email Alerting Receive free email alerts when new articles cite this article - sign up in the box at the top Service right corner of the article or click here.

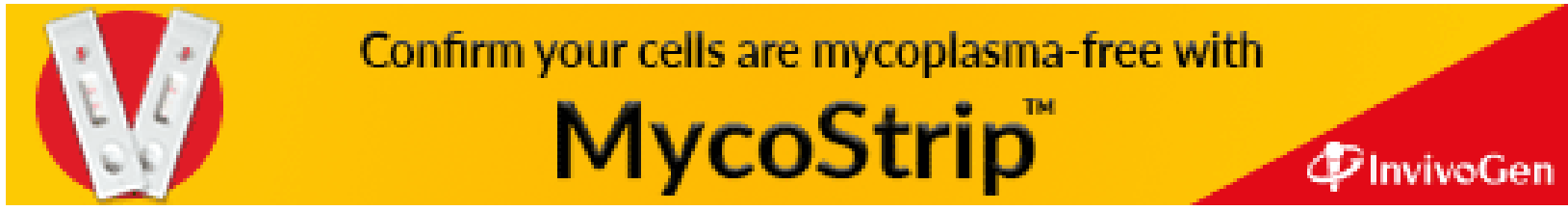

